\title{
Carcinoma of esophagus
}

INSERM

\section{Source}

INSERM. (1999). Orphanet: an online rare disease and orphan drug data base. Carcinoma of esophagus. ORPHA:70482

Esophageal carcinoma (EC) is a tumor arising in the epithelial cells lining the esophagus and can be divided into two subtypes: esophageal squamous cell carcinoma (ESCC) and esophageal adenocarcinoma (EAC). 